\title{
DIGITALISATION AND AUTOMATION IN PHARMACEUTICALS FROM DRUG DISCOVERY TO DRUG ADMINISTRATION
}

\author{
ABDUL MANNAN, HAJERA MUBEEN* \\ Department of Pharmaceutics, Deccan School of Pharmacy, 500001, Hyderabad, India \\ Email: hajmubeen@gmail.com
}

Received: 13 Jan 2018 Revised and Accepted: 08 May 2018

\begin{abstract}
The rapid progress in the pharmaceutical industry is due to the advancement in the digitalization and automation starting from the invention to the administration of the drug. Every advancement in the development of the pharmaceutical product is associated with progress in digitalization. A drug or a drug product to be administered safely and to provide efficacy it has to undergo a long journey from its discovery, including pre-clinical and clinical trials to further product development in the research and development. The production and manufacturing systems with appropriate digitalization and automation compile the drug formulation after the servitude of the research and development (RandD) department. Later, the quality control and quality assurance systems utilize digitalization to maintain the quality and standard of the drug product. Subsequently, packaging and labeling of the drug product are carried out with effective automation. Further, the marketing and supply of the drug products are digitally monitored and dispatched to the distributors and the pharmacies. Finally, the drug product will be dispensed to the patient for its administration with a concordance of digitally monitoring for enhanced efficacy and safety. Therefore, in this review article, various strategies for digitalization and automation in the pharmaceuticals from drug discovery to drug administration are briefly discussed.
\end{abstract}

Keywords: Digitalization, Automation, Pharmaceutical Industry, Drug Products and Computer Aided Design

(C) 2018 The Authors. Published by Innovare Academic Sciences Pvt Ltd. This is an open access article under the CC BY license (http://creativecommons.org/licenses/by/4.0/) DOI: http://dx.doi.org/10.22159/ijpps.2018v10i6.24757

\section{INTRODUCTION}

The lifeblood of any industry is innovation, the discovery and development of new medicines are worked out with unique challenges, ethical implications and social responsibilities also the process seems arcane. Information from scientists from the different department is required in the process, e. g., expertise in molecular biology, physiology, biochemistry, analytical and medicinal chemistry, crystallography, pharmacology, and even more distant areas such as information science and robotics [1]. Preclinical and clinical investigations are conducted slow, upscale and requires about 800 million USD to 1 billion USD in about $15 \mathrm{y}$. various software's help to predict the interactions, toxicities, thereby accurately defining the success of a novel compound [2]. The in silico experiments in research and development (RandD) are used to speed up the development process of the solid dosage form and to replace the pricey laboratory experiments [3]. Robots are used in filling, inspection, packaging and for producing personalized medicines [4]. Digital social media provides a direct interaction of customers with the marketers thereby upgrading the marketing strategies [5]. Electronic prescription, paperless technology is received at the pharmacy by the patients, providing better patient compliance [6].

Selected reference articles for this review were taken by using different keywords like Automation and Digitalization in pharmaceuticals, Computer used in pharmaceuticals, Software used in pharmaceuticals including drug discovery to drug development and drug filing electronically, between 1990-2017 from various sources like Google Scholar, PubMed, and Science Direct.

\section{Prediscovery or target discovery}

Prediscovery is the process of understanding the disease and choosing a valid target molecule.

On the basis of studies associated with biological mutations and disease states pharmaceutical researchers formulate hypotheses about the mechanism of actions involved they study how genes have changed, how these changes affect the proteins encoded by the genes, how these proteins interact with each other in living cells, how the affected cells change the specific tissue they are in, and how all these processes combine to affect the patient followed by selecting a biological target [7].

\section{Drug discovery}

Finding promising leads (an organic or other drug molecules that may act on the target to alter the disease course) for a drug candidate. A set of possibilities is embellished with the headway in biotechnology, where scientists develop living systems genetically to produce disease-fighting biological molecules. A variety of drug source is provided by combinatorial chemistry, it enables the quick generation of molecules to exacerbate the chemical diversity if the known molecule libraries. The easiest way for screening the already existing libraries to find the compounds that can modify the chosen target without affecting any off-target molecules is the high throughput screening [8]. Also, the X-ray crystallography and nuclear magnetic resonance (NMR) helps to identify the structure of the molecule. After many iterations, the final compound becomes a drug candidate [8].

In the drug designing, the in silico analysis has been performed using Windows operating system which is implemented with Maestro Software package. This package was provided by Schrodinger, implementing the desired modules Glide, Phase, LigPrep and Quik prop $[11,12]$.

\section{Preclinical trials and clinical trials}

Randomization is applied by the software to remove bias and to plan study design. In the preclinical trials softwares like electronic data capture, remote data capture and electronic case report form (eCRF) are used to store the data. For the clinical data management and statistical analysis of the data softwares like eClinical and Oracle clinical, clinical conductor clinical trial management system (CTMS) (by Bio-Optronics), Clindex, Ascend (by Biopharm) are being used effectively. They aid in the planning, data collections, data accession, exchange, and for the execution, management, analysis, and reporting of the trial is carried out electronically [13-16]. The electronic data capture (EDC) provides an ease of entering the information directly into the software over an internet connection [17-21]. 
Big data management (BDM) technologies help in solving the data storing issues and support specialized tools and facilities that can be used for normalizing and harmonizing data, used by advanced analytics. With big data mangement (BDM), the medical records and follow-up data can be more efficiently stored and extracted [22-24].

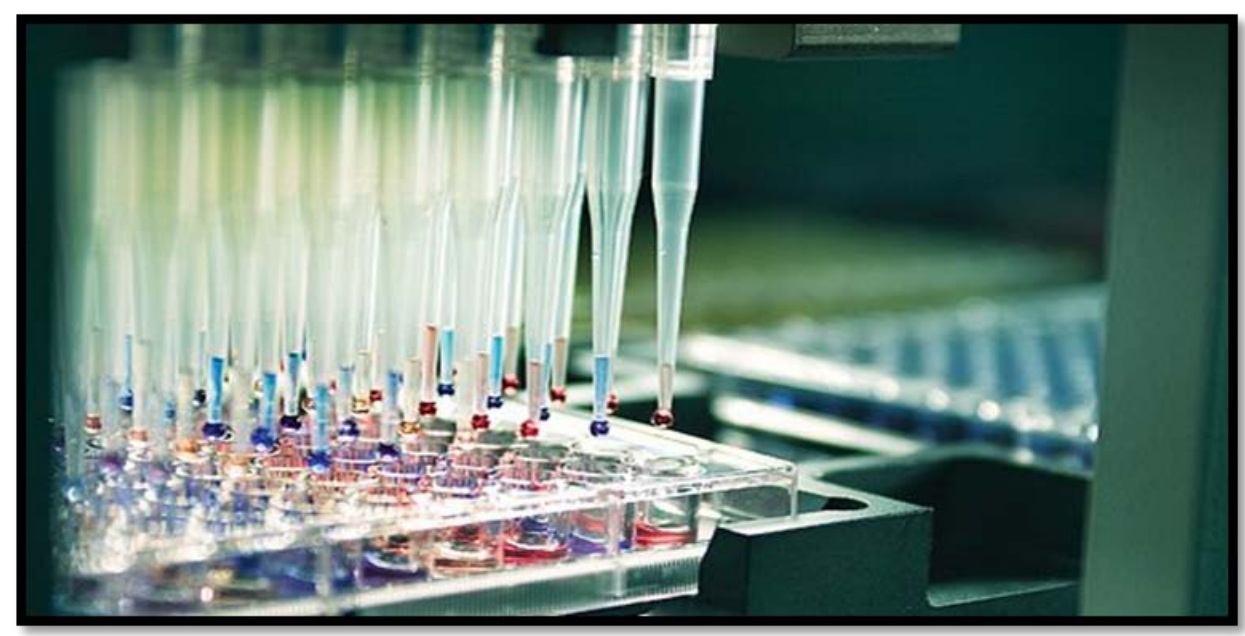

Fig. 1: High throughput screening technique to screen the existing libraries of compounds [9]

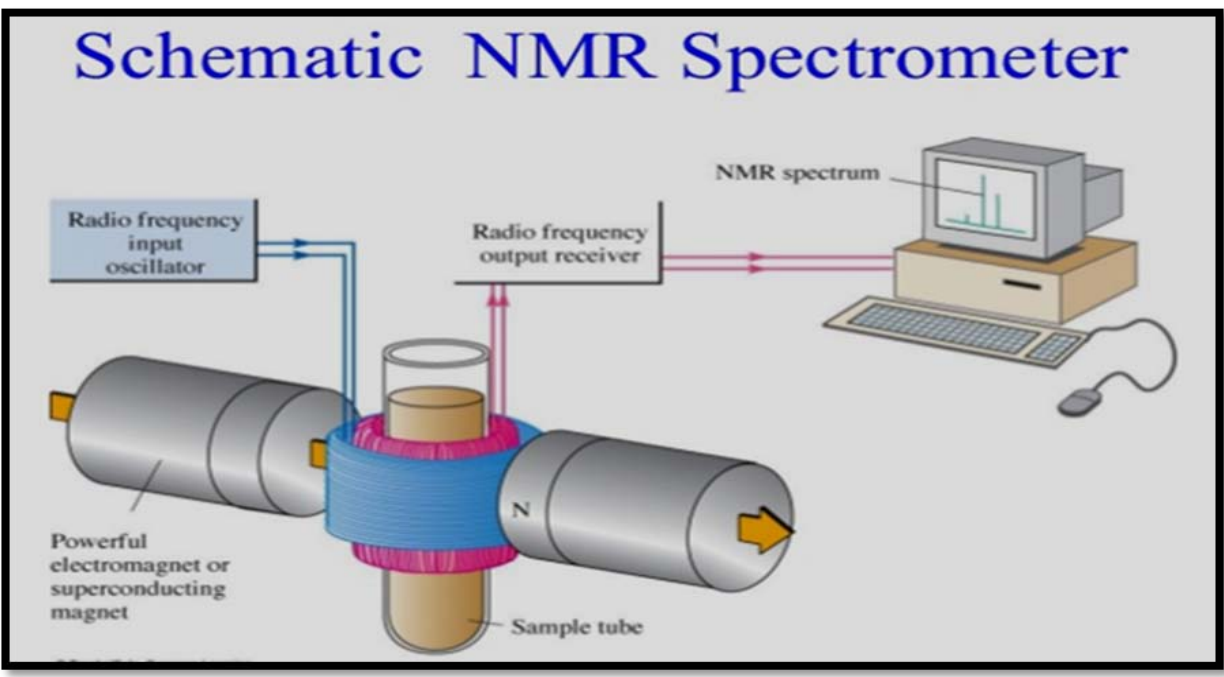

Fig. 2: Nuclear magnetic resonance (NMR) spectrometer to identify the structure of the molecule [10]

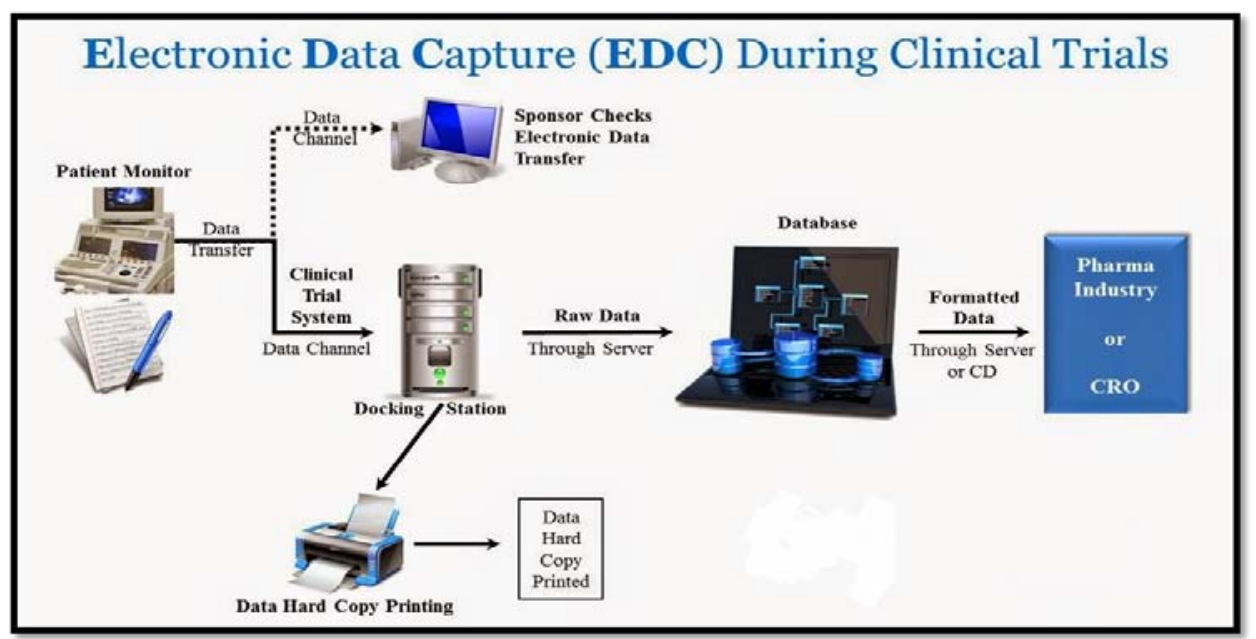

Fig. 3: Electronic data capture (EDC) during clinical trials [25] 


\section{Filing of new drug application}

The regulatory submissions in the electronic format are accredited by the Food and Drug Administration (FDA) to the Center for Drug Evaluation and Research (CDER) and the Center for Biologics Evaluation and Research (CBER) [26]. Submissions are carried out using the electronic common technical document (eCTD). After the information is submitted to the Food and Drug Administration (FDA) and the attainment of the receipt, the report is submitted electronically through the electronic submission gateway (ESG) [26].

\section{Research and development}

The in silico experiments are carried out for the research and development. For the virtual research and development (e-RandD) the in silico experiments are performed using hardware and software package of the formulation-computer aided design (FCAD) $[27,28]$. Another science used in the research and development
(RandD) is Robotics, the technology of robots that possess the electro-mechanical system [29].

The formulation-computer aided design (F-CAD) is designed by the software modules which is based on the concept of cellular automata to calculate dissolution profiles of the drug substance as a function of the composition and of the physicochemical properties of the components in a formulation (solubility, swellability, effect of the particle size distribution of the drug substance and the excipients, etc.) [30, 31].

\section{3-Dimensional (3D) printing technology}

A unique prototyping technology the three-dimensional technology can fabricate solid dosage forms with different densities and diffusivities, complex internal geometrics, multiple drugs, and excipients. It uses computer aided drafting (CAD) technology and programming to produce a 3-Dimensional (3D) object by layering material onto a substrate [32].

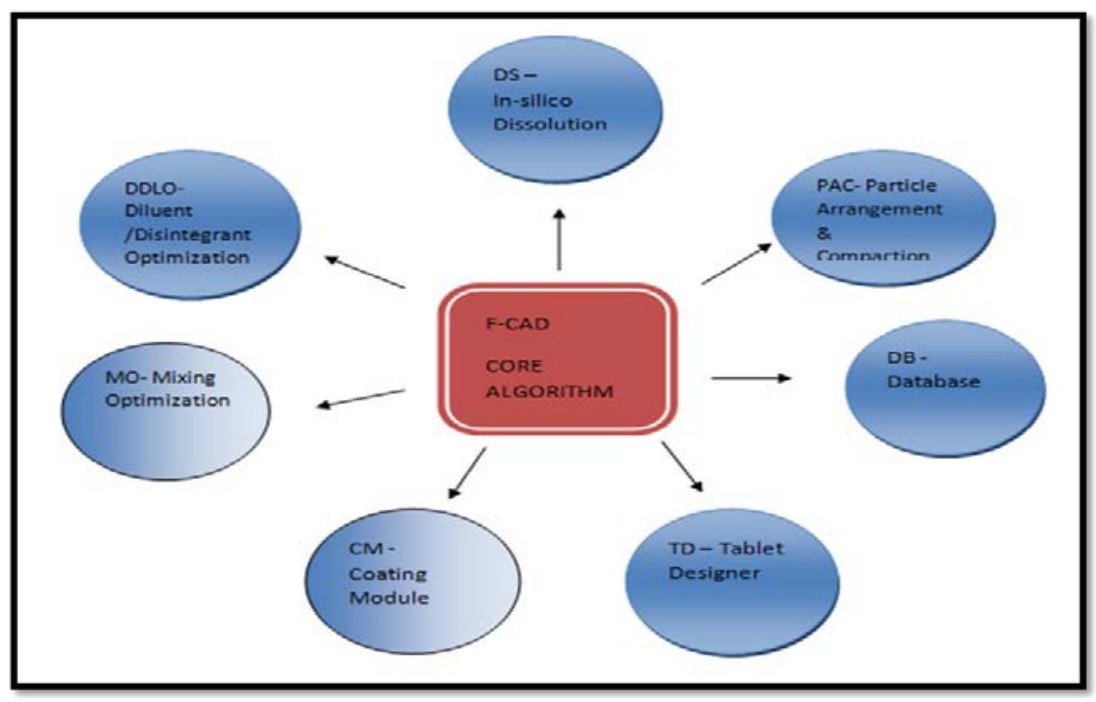

Fig. 4: Formulation-computer aided design (F-CAD) software modules: the semi-filled circles indicate that this module has been complemented with discrete element methods [30]

Table 1: Types of printers in 3D printing technology

\begin{tabular}{llll}
\hline Printing technology & Dosage forms & Model drug used & Reference \\
\hline 3D Powder direct printing technology & Microporous bioceramics & Tetracyclin, Vancomycin & {$[33]$} \\
Fused filament 3D printing & Tablets & Flouroscene & {$[34]$} \\
Piezoelectric inkjet printer & Microparticles & Paclitaxel & {$[35]$} \\
Microdrop inkjet printer & Nanosuspension & Folic acid & {$[36]$} \\
Stereolithography printer & Anti-acne patch & Salicylic acid & {$[37]$} \\
\hline
\end{tabular}

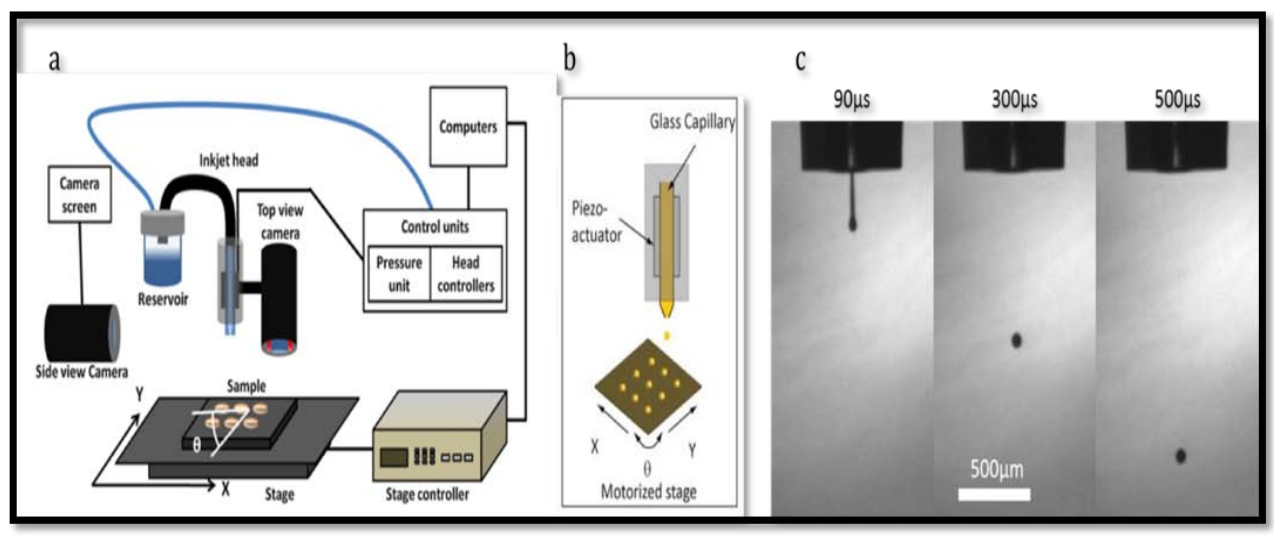

Fig. 5: Schematics of a) Microfab inkjet printer and b) dispenser, c) micro-drop generation [38] 


\section{Production and manufacturing}

Manufacturing is a tool of the Pharmaceutical Industry wherein the production and manufacturing of the drug product are made out of materials using machines or robots. With the development of the Automation processes in the industry, the modern contemporary automation applied could be fixed or hard automation, flexible automation, and programmable automation. The computer integrated manufacturing (CIM) and computer aided manufacturing (CAM) systems are applied to product development and manufacturing activities. These advanced manufacturing systems include three types of manufacturing:

1. Intelligent manufacturing

2. Virtual manufacturing

\section{Internet controlled manufacturing [39]}

\section{Robots for producing personalized medicines}

The biopharmaceutical partnered companies Invetech and Argos Therapeutics developed an automated manufacturing system based on Argos' Arcelis Technology for personalized immunotherapy, which uses two, five-axis robotic arms to produce messenger Ribonucleic acid (mRNA) from a patient's tumor used as the antigen for loading into the dendritic cells produced in the cellular processing equipment. The cellular equipment uses automation to manipulate the white blood cells throughout the manufacturing process to control their development and maturation into dendritic cells. These cells express the desired antigens, which when delivered to a patient, will trigger the patient's immune system to produce killer T-cells that will target the metastatic tumors [40].

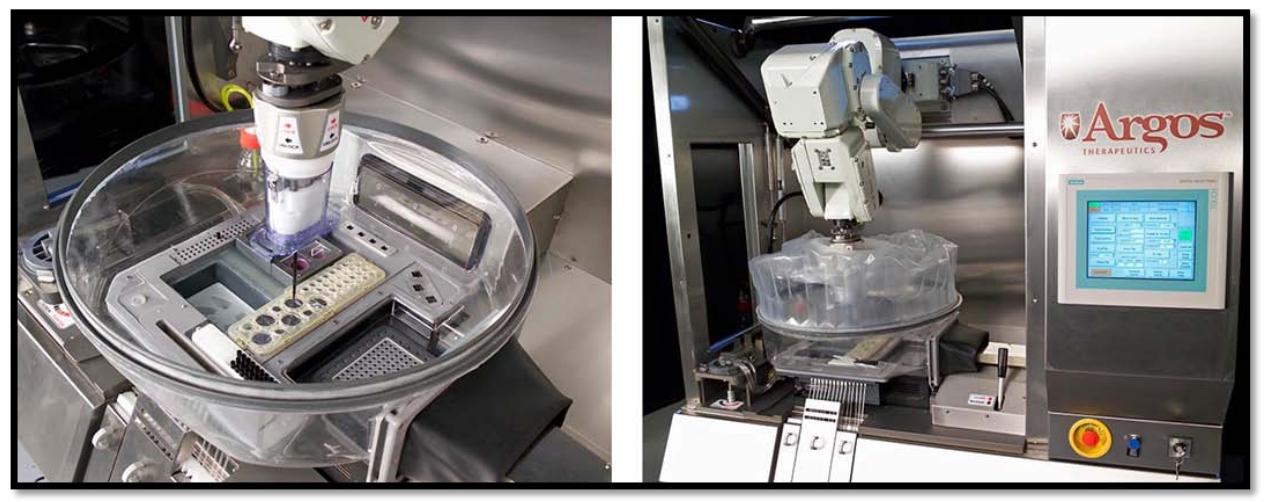

Fig. 6: Invetech using argos' arcelis technology for production of patient specific immunotherapies [41]

\section{Paperless manufacturing executing system}

The paperless manufacturing in actual terms is the application of software-based electronic systems to monitor and enforce manufacturing production processes while capturing all information associated with production records. Higher level systems such as ERF integrate Paperless systems to get an account of material information and orders to manage on the plant floor. There are many advantages of this system over the paper-based manual systems. The former cater the error-proofing and real-time visibility necessary to produce consistent product quality, also dramatically expedite the final review and release time by waiving the need for manufacturing review [42].

\section{Digitalization in quality control and quality assurance}

Considering quality control and assurance, quality control at its core is a reactive process, the premarket checks and inspections assure pharmaceutical manufacturers of the standard of the product or drug [43].

Table 2: Quality control vs quality assurance [43]

\begin{tabular}{ll}
\hline Quality control & Quality assurance \\
\hline Product & Process \\
Reactive & Proactive \\
Corrective tool & Preventive tool \\
Completed by experts & Implemented by managers \\
Ensures and checks & Develops and defines \\
Failure detection & Failure prevention \\
Identify and correct defects & Prevents defects \\
Identification through inspections and peer review & Prevention with statistical and managerial tools \\
\hline
\end{tabular}

Pharmaceutical quality control is generally referred by the International Conference on Harmonization (ICH) Q10 model which is based on International Organization for Standardization (ISO) quality concepts, including Good manufacturing practices (GMP) and complements International Conference on Harmonization (ICH) "Q8 Pharmaceutical development" and International Conference on Harmonization (ICH) “Q9 Quality Risk Management".

International Conference on Harmonization (ICH) Q10 has three main objectives:

- Achieve product realization.

- Establish and maintain a state of control.
- Facilitate continual improvement [44].

\section{- Quality risk management}

It provides a proactive approach in the identification, scientific evaluation and control potential risks to quality. It facilitates continual improvement of process performance and product quality throughout the product lifecycle [44].

\section{Q Quality by design}

It is a quality system to manage the product's lifecycle. It is a multifunctional exercise intended to increase process and product understanding and thereby decrease patient's risk. Quality by 
Design $(\mathrm{QbD})$ is a process defined by documentation requirements [45].

Primary Quality by Design (QbD) documents:

- Risk assessment report(s)

- Quality target product profile

- Control strategy summary

- PPQ report(s)
- Continued process verification (CPV) Reports [45]

४ Quality by design (QbD) and new process development

The goal of process development is the creation of a process control strategy. The Quality by design $(\mathrm{QbD})$ process is iterative can have multiple feedback modes [45].

The outcome of Quality by design (QbD) is a well-designed and understood the quality product that consistently delivers the continuous performance [45].

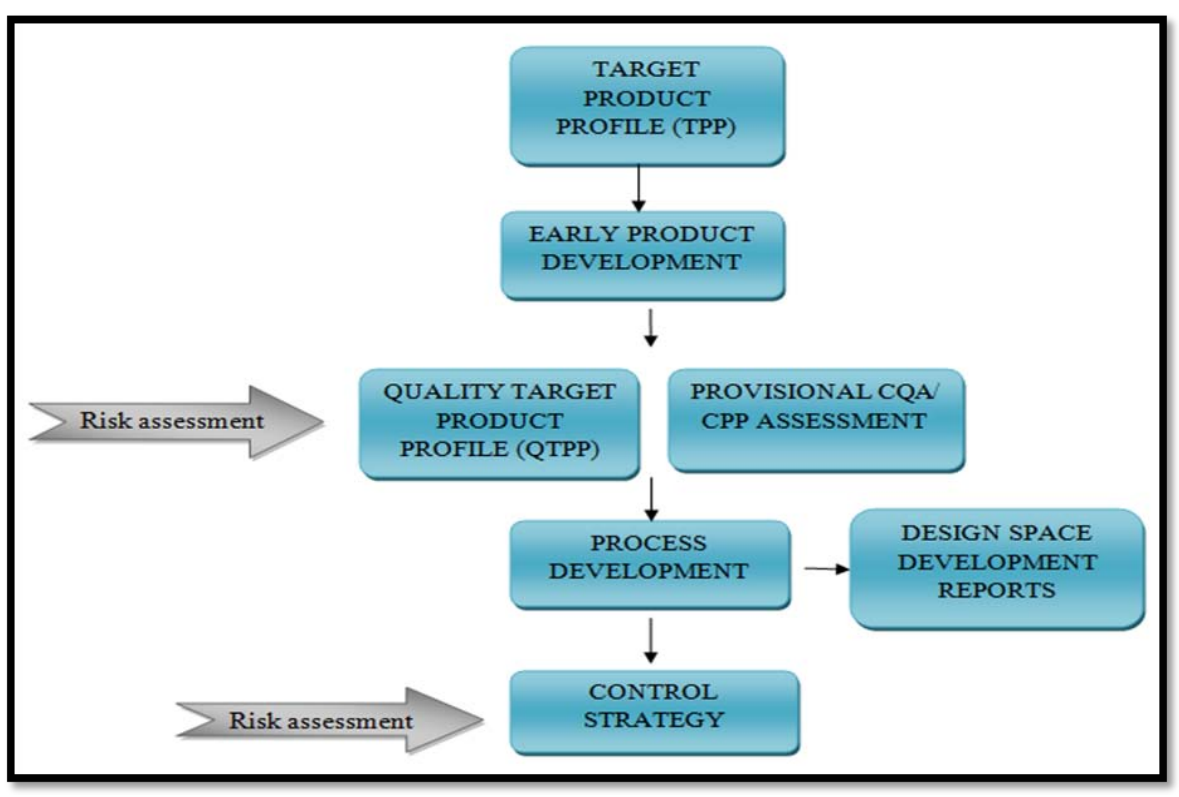

Fig. 7: Quality by design (QbD) and new process development [45]

This approach has been used to get method operable design region (MODR) for the development of spectrophotometric and fluorometric methods for the estimation of Darunavir, also to advance product and process quality, particularly in automotive industry [46-50].

\section{- Process analytical technology (PAT)}

Process analytical technology (PAT) is a key element of the "Pharmaceutical Current Good Manufacturing Practices (CGMPs) for the 21st Century-a Risk-Based Approach" initiative announced by the FDA in August 2002 to improve and modernize pharmaceutical manufacturing. Process analytical technologies (PAT) is used to provide and inform the timely analysis of critical quality parameters with the end goal of improving final product quality as well as reducing manufacturing costs, thereby significantly benefiting the Pharmaceutical Industry in the manufacturing area. Process analytical technologies (PAT) involves the use of raw material properties, process monitoring, manufacturing parameters and chemometric techniques to produce finished products of acceptable quality and purity [51].

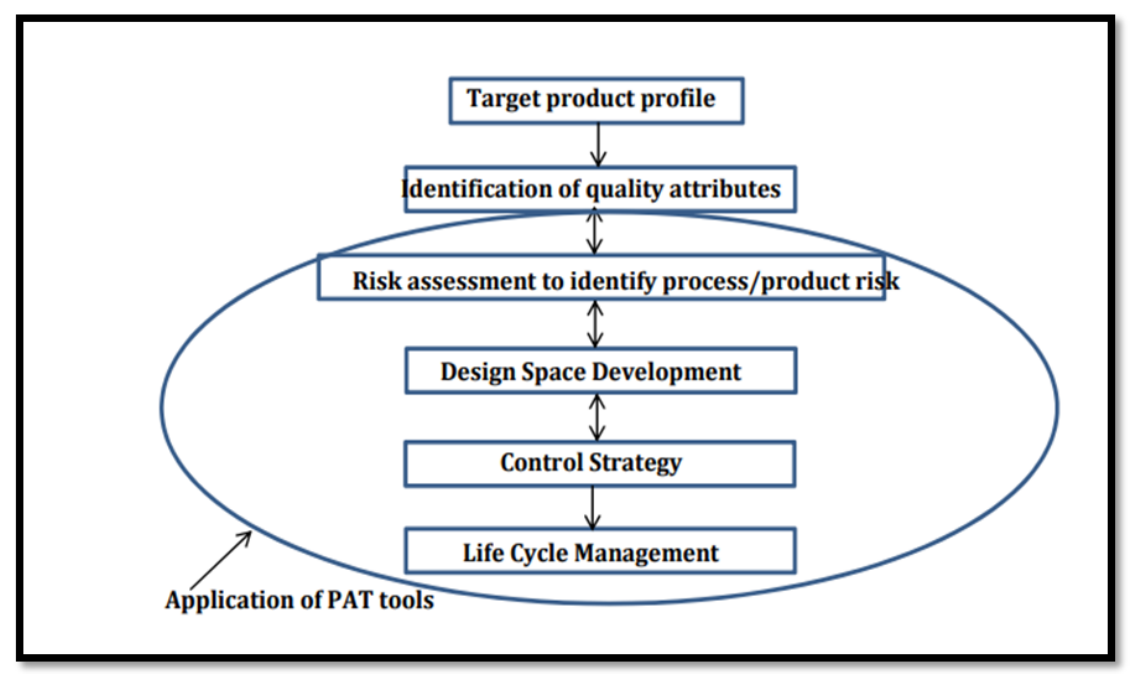

Fig. 8: Elements of quality by design (QbD) [52] 


\section{Packaging and labeling}

The pathway of Packaging uses different types of machinery for cartooning, wrapping, labeling, shrinking, sealing, case and tray forming, capping, cooling and drying, feeding, palletizing, picking and placing (robotic systems), cleaning and sterilizing, in addition to inspection and detecting machines.

There are different techniques involved in packaging. Modified atmosphere packaging (MAP) is a technique employed to artificially reduce oxygen level and inflate carbon-di-oxide level. Smart packaging is an advanced packaging pertinent to use of intelligent sensors. Nanotechnology-based sensors for packaging are used for pathogen and contaminant detection and tracking [53].

Anti-Counterfeit Technology is enforced to combat counterfeiting of the drug products $[54,55]$.
Anti-Counterfeit Technologies can be used in three ways:

1. Tamper-Evident/tamper-resistant packing: This type of packaging provides an indicator or barrier to entry which, if breached or missing show visible or audible evidence to consumers that tampering has ensued. Eg. Film wrappers, shrinkable seals and bands, breakable caps, tape seals, blister packs, etc [56].

2. Product authentication: Authentication features can be embedded either on the dose or in the packaging of the medicines [57].

3. Track and Trace Technology: Assigns a unique identity to each stock unit in the process of manufacture which is continued via the supply chain till its consumption. Information is attached in the form of a unique pack coding, enabling access to the same information on a secure database [57].

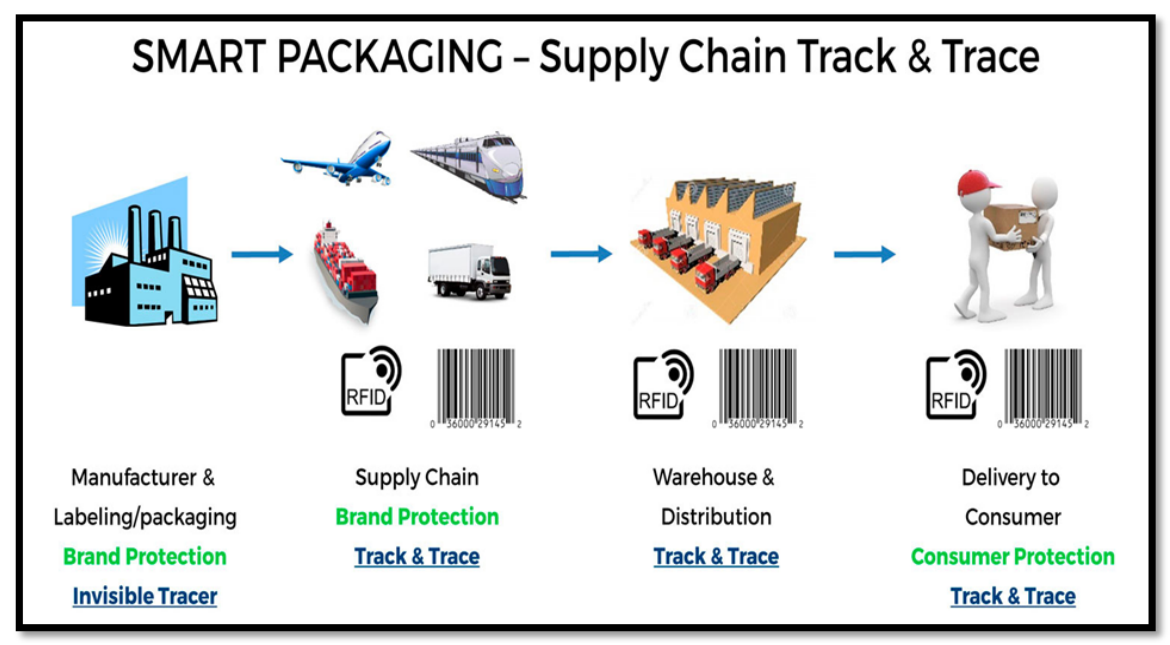

Fig. 9: Smart packaging using track and trace technolog [58]

Techniques such as Mass Serialization and Data Carriers (RFID and Barcodes) are also helpful in Packaging and Labeling

\section{- Radio frequency identification (RFID)}

Radio frequency identification (RFID) is an automated data collection technology that utilizes radio-frequency waves to transfer data or information between a reader and a movable item to identify categorize and track. It provides unique identification and backend integration for accessing a wide range of applications [59].

\section{Sales and marketing}

The tedious process is the paper-based process that is costly per batch, inefficiency, and risk in the form of human errors. To change the game, Electronic batch recording has replaced the old method of paper documentation with a more agiler software-driven System to manage workflows and recordkeeping for everything from recipe creation to batch qualification [60].

This is used to speed up the review time for batch documentation, retrieve batch protocols, and eliminate the need to pass records physically between stations [60]. Online professional and patient communities have developed to adapt increased usage of mobile, social media, as well as online information by patients, healthcare professionals (HCP), key opinion leaders (KOL) and the larger medical fraternity, have instigated pharmaceutical companies to invest and explore digital marketing strategies within industry guidelines [61].

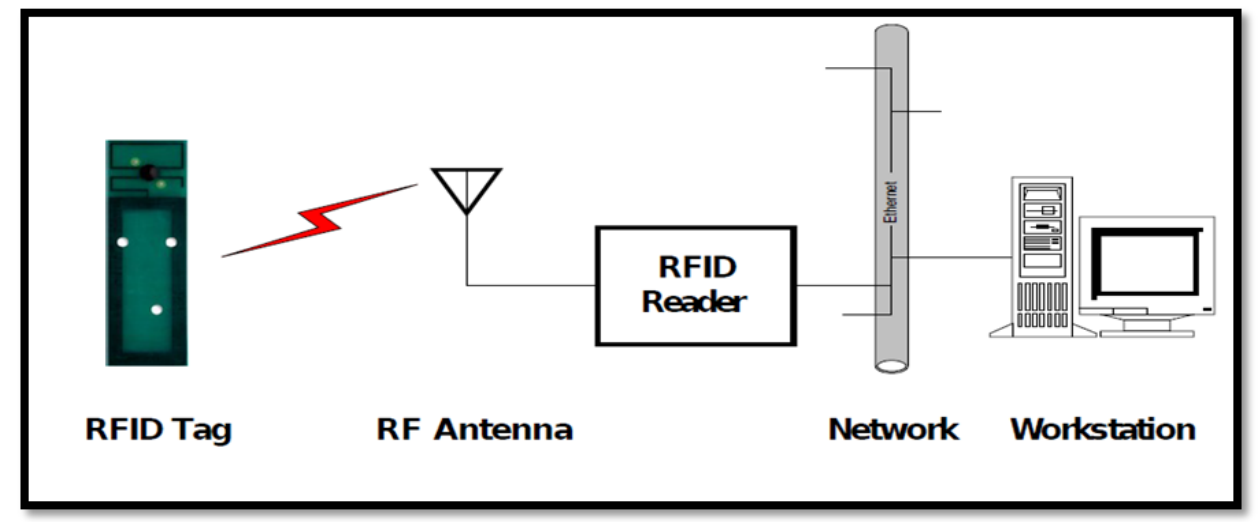

Fig. 10: Portraiture of radio-frequency identifier technology [59] 
A continuous interaction between customers and the marketers is provided by the digital media. The pharmaceutical companies are adopting new online media, namely electronic detailing (e-Detailing) to promote the medicines to physicians. The modest attempts made by this inclination are blooming of Apps by the pharmaceutical companies. In the pharmaceutical companies, Johnson and Johnson was one of the first to launch a YouTube channel. Offer to online order special medicines, to promote e-commerce and digital marketing was provided by Quantum Pharmaceuticals and The Specials Lab, North East based pharmaceutical companies [61].

\section{Types of digital marketing used are}

1. Search engine optimization (SEO).

2. Social Media Marketing.

3. Pay Per Click Ads.

4. E-Mail Newsletters [61].

\section{Dispensing pharmacy}

Techniques are developed for the ease of the dispensing which likely includes electronic prescription $(\mathrm{eRx})$ and electronic repeat design
(eRD). In electronic prescription (eRx), the pharmacies directly receive the prescriptions from the doctors, a paperless prescription. Electronic prescribing is an aid in the safety as it provides a secure access the patient's prescription history to the doctors and helps them prescribe the drugs that will not interact with other prescription drugs that the patient might take.

It provides serenity to the pharmacist by the less chance of accidentally giving the wrong drug or dose which might be caused due to the handwritten prescriptions.

Electronic prescription (eRx) helps the doctors to check the insurance covers the patient in order to prescribe a covered drug that the patient could afford [64].

Electronic repeat design (eRD) is a technique that allows the prescriber to authorize and issue a batch of repeatable prescriptions for up to 12 mo with one digital signature. eRD stores all issues of the electronic repeat design (eRD) prescriptions securely on the National Health Service (NHS) Spine and delivers them to the patient's nominated dispenser at the intervals set by the prescriber. The prescriber retains the ability to change or cancel the prescription at any time [65].

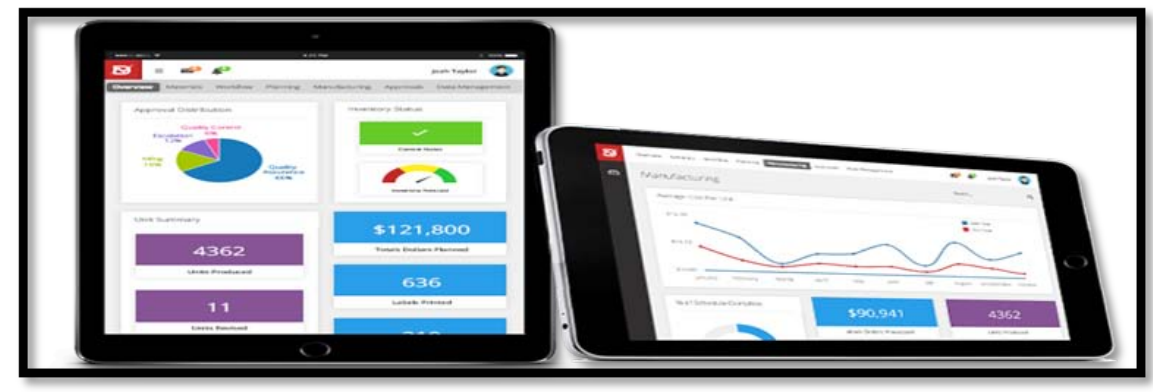

Fig. 11: Electronic batch recording (EBR) software [62]

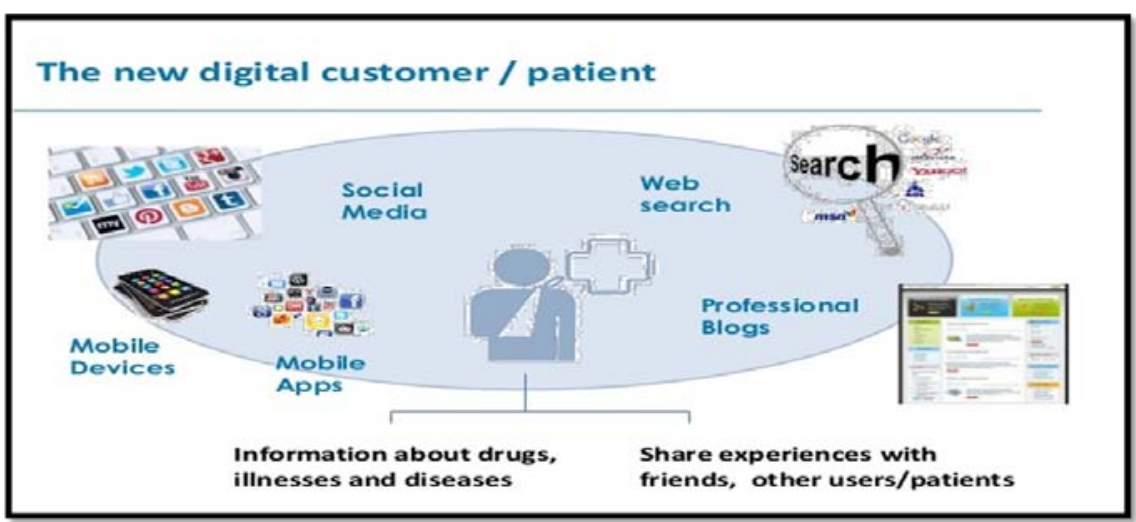

Fig. 12: Digital customer/patient [63]

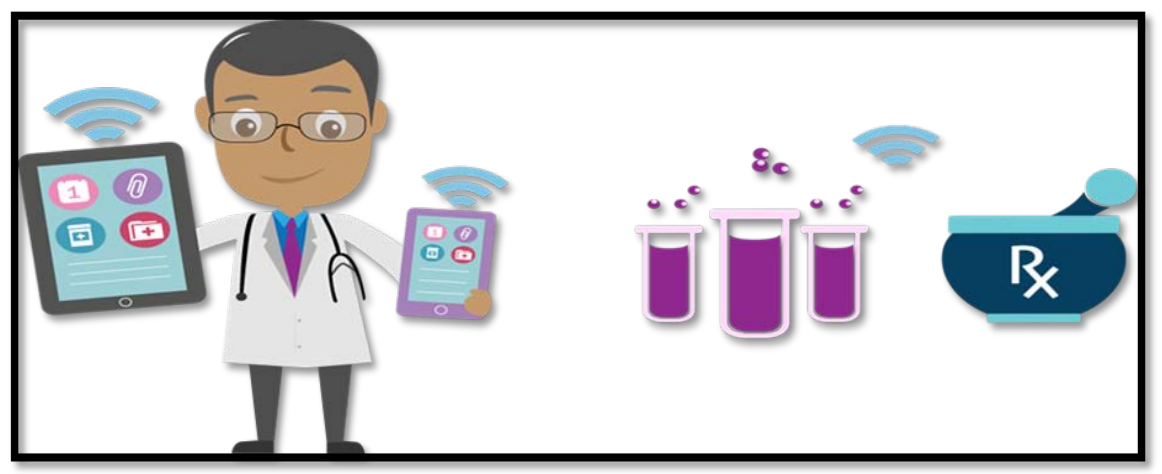

Fig. 13: e-prescription (eRx) [66] 


\section{Digital strategies for monitoring drug administration}

Drug Monitoring is an important factor in the healthcare of the patients. The electronic drug monitoring systems (eDMS) are used to evaluate the time nurses spend on clinical documentation. It is carried out for the safety concerns, high potential for error and can be assisted with the use of information and communication technology (ICT). The electronic drug monitoring systems (eDMS) are a combination of both manual and electronic systems [67-69].

The prescription drug monitoring programs (PDMPs) is a statewide electronic database that tracks all the controlled substance prescriptions. There is an access to the authorized users to the prescription data, such as medications dispensed and doses. The programs subject to improving the way, opioids are prescribed will ensure patients have access to safer, more effective chronic pain treatment while reducing opioid misuse, abuse, and overdose [70].

\section{- Drug monitoring and healthcare applications}

In the market of applications, there are free and premium medical apps, some that allow a better understanding about pharmaceuticals while others work to diagnose the symptoms and help to prepare for an unforeseen medical emergency [71].

- Micromedex: Reference app with features such as proper drug dosage and medicine recommendations.
- Johns Hopkins ABX guide allows you to search for information on medications and treatments regarding various illnesses.

- The Red Cross' official first aid app provides simple step-by-step instructions to guide for everyday first aid scenarios, whether to consider asthma attacks or broken bones.

- Mychart: Allow you to access your medical records on your phone at any time.

- Epocrates: It not only does the robust offering supplybasic information regarding the side effects and dosage amounts of various prescription drugs but also provide the access to contact their manufacturer directly.

- Doctor on demand: This convenient app aids, to instantly connect with the licensed professionals via video chats and audio calls, thus granting an ease of access to medical advice and prescriptions based on particular symptoms without stepping out of the door.

- Medscape medpulse is a news aggregator designed for anything and everything related to the world of medicine. The app provides you with an onslaught of articles, written specifically for physicians, students, and healthcare professionals.

- WebMD allows people to set medication schedules, create a process with which they can use to meet a personal health goal, and check for local physicians and pharmacies which patients may be unaware [71].

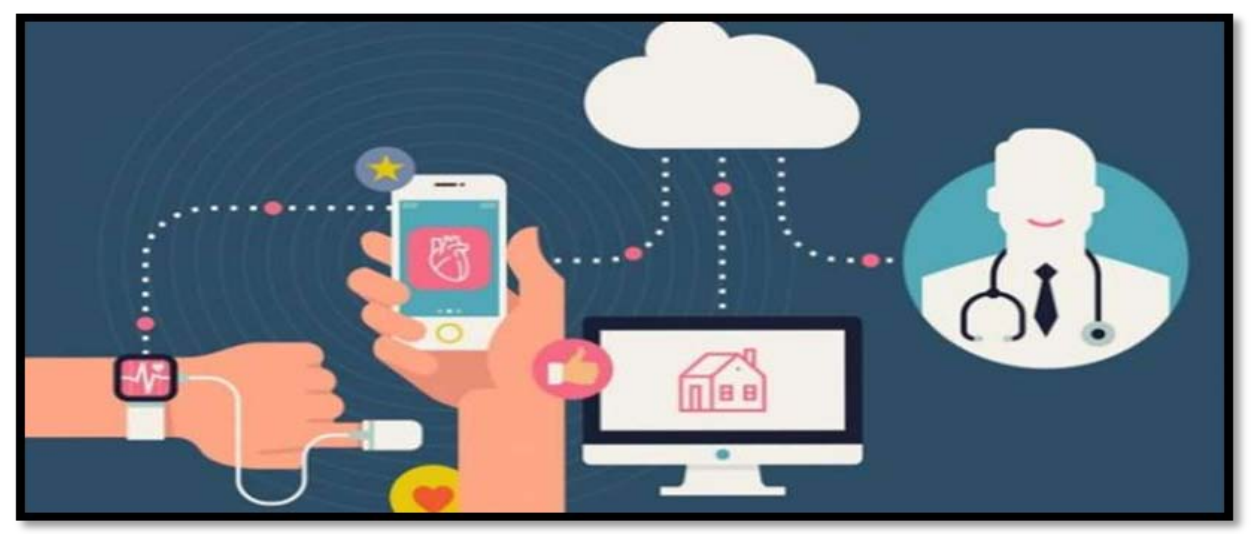

Fig. 14: Drug monitoring and healthcare applications [72]

\section{CONCLUSION}

The digitalization and automation process in the pharmaceutical industry is rapidly growing, many devices, robots, and softwares have been used. Advanced analytics, sensors, and the automation of complex decisions are adept at delivering a step change in the efficiency, speed, quality, and responsiveness of processes in every industry. These are employed for the development of the process and to obtain a better drug product with enhanced efficacy. Maximum advancement in the drug distribution and dispensing of the pharmaceutical product is associated with progress in digitalization. However, even after these many advancements in the digitalization of the pharmaceuticals still, there is a scope for innovation and advancement in the development of pharmaceuticals.

\section{AUTHORS CONTRIBUTIONS}

All the author have contributed equally

\section{CONFLICT OF INTERESTS}

\section{Declared none}

\section{REFERENCES}

1. Petrova E, Ding M, Eliashberg J, Stremersch S. Innovation and marketing in the pharmaceutical industry. [S. l.]: SpringerVerlag New York 2014;7:19-81.
2. Bansal P, Gill S, Christopher A, Gupta V. Emerging role of bioinformatics tools and software in evolution of clinical research. Perspect Clin Res 2016;7:115-22.

3. Leuenberger $\mathrm{H}$, Leuenberger MN. Implementing virtual $\mathrm{R}$ and $\mathrm{D}$ reality in industry: In silico design and testing of solid dosage forms. Virtual R and D reality/proof of concept. Swiss Pharm 2009;31:18-21.

4. Markarian J. Using robotics in pharmaceutical manufacturing, equipment and processing report, [Internet]. Pharmtech.com. Available from: 2014. Available from: http://www. pharmtech.com/ using-robotics-pharmaceuticalmanufacturing.[Last accessed on 25 Mar 2018]

5. Ranganathan S, Bellani V. Digital marketing in the indian pharmaceutical industry: a study to assess views of pharmaceutical marketing professionals in using digital marketing as a brand promotional lever. World J Pharm Pharm Sci 1970;89:5, 2278-4351.

6. Mahnaz S, Ahmadi M, Sadoughi F, Garavand A. A copmarative review of electronic prescription systems: lessons learned from developed countries. J Res Pharm Pract 2017;6:3-11.

7. Acemoglu D, Linn J. Market size in innovation: theory and evidence from the pharmaceutical industry. Quart J Econ 2004;119:1049-90.

8. Cassiman B, Ueda M. Optimal project rejection and new firm start-ups. Manag Sci 2006;52:262-75. 
9. High-Throughput Screening and Compound Screening Service | Medicilon Inc. Medicilon.com; 2017. Available from: http://www.medicilon.com/high-throughput-screeningservice/. [Last accessed on 22 Apr 2018]

10. Saurav R. NMR (Nuclear Magnetic Resonance) [Internet]. Slideshare.net; 2014. Available from: https://www. slideshare.net/RawatDAGreatt/nmr-40157983. [Last accessed on 25 Mar 2018]

11. Devi B, Rajagopal K, Elizabeth E. Pharmacophoric screening of various endophytic fungal metabolites. Asian J Pharm Clin Res 2017;10:140-6.

12. Saxena S, Devi P, Soni V, Yogeeswari P, Sriram D. Identification of novel inhibitors against Mycobacterium tuberculosis Lalanine dehydrogenase (MTB-AlaDH) through structure-based virtual screening. J Mol Graph Model 2014;47:37-43.

13. Zerhouni EA. Clinical research at a crossroads: the $\mathrm{NIH}$ roadmap. J Investig Med 2006;54:171-3.

14. Chang J, Zhu X. Bioinformatics databases: Intellectual property protection strategy. J Intellect Property Rights 2010;15:447-54.

15. Liu Y, Hu B, Fu C, Chen X. DCDB: Drug combination database. Bioinformatics 2009;26:587-8.

16. Liu X, Wang S, Meng F, Wang J, Zhang Y, Dai E, et al. SM2miR: a database of the experimentally validated small molecules' effects on microRNA expression. Bioinformatics 2013;29:409-11.

17. Raviteja M, Gupta N. A review on electronic data management in pharmaceutical industry. Asian J Pharm Clin Res 2013;6:38-42.

18. Richard C, Bairu M. Global clinical trials: effective implementation and management. Elsevier Academic Press; 2011. p. 471-522.

19. Edwards R, Edwards S. A computer-assisted data collection system for use in a multicenter study of American Indians and Alaska Natives: SCAPES. Computer Methods Programs Biomed 2008;90:38-55.

20. Pavlović I, Kern T, Miklavcic D. Comparison of paper-based and electronic data collection process in clinical trials: costs simulation study. Contemporary Clinical Trials. Elsevier 2009;30:300-16.

21. Collada A, Fazi P, Luzi D, Ricci F, Serbanati L, Vignetti M. Toward a model of clinical trials. Proceedings of the 5th international symposium ISBMDA; 2004. p. 299-312.

22. Barrett T, Suzek TO, Troup DB, Wilhite SE, Ngau WC, Ledoux P, et al. NCBI GEO: Mining millions of expression profilesdatabase and tools. Nucleic Acids Res 2005;33:562-6.

23. Brylinski M, Skolnick J. A threading-based method (FINDSITE) for ligand-binding site prediction and functional annotation. Proc Natl Acad Sci U S A 2008;105:129-34.

24. Huang L, Li F, Sheng J, Xia X, Ma J, Zhan M, et al. Drug combo ranker: Drug combination discovery based on target network analysis. Bioinformatics 2014;30:228-36.

25. Electronic Data Capture (EDC) During Clinical Trials [Internet]. Clinnovo. blogspot.in; 2015. Available from: http://clinnovo.blogspot.in/2015/01/electronic-data-captureedc-during.html. [Last accessed on 25 Mar 2018]

26. Guidelines, Guidance for industry; Providing regulatory submissions in electronic format [Internet]. Justia Regulation Tracker; 2014. p. 7463-4.

27. Maurer L, Leuenberger H. Application of near infrared spectroscopy in the full-scale manufacturing of pharmaceutical solid dosage forms, Pharm Indian 2009;71:672-8.

28. Maurer L, Leuenberger $H$. Terahertz pulsed imaging and near infrared imaging to monitor the coating process of pharmaceutical tablets, Int J Pharm 2009;370:8-16.

29. Kabra MP, Kabra D, Somani G. A review on role of robot in pharmaceutical industry. Int J Instl Pharm Life Sci 2011;1:220-37.

30. Leuenberger H, Bonny J, Kolb M. Percolation effects in matrixtype controlled drug release systems. Int J Pharm 1995;115:217-24.

31. Krausbauer E, Puchkov M, Betz G, Leuenberger H. Rational estimation of the optimum amount of non-fibrous disintegrant applying percolation theory for binary fast disintegrating formulation. J Pharm Sci 2008;97:529-41.
32. Maulvi FA, Shah MJ, Solanki BS, Patel AS, Soni TG. Application of 3D printing technology in the development of novel drug delivery systems. Int J Drug Dev Res 2017;9:44-9.

33. Gbureck U, Vorndran E, Muller F, Barralet J. Low temperature direct 3D printed bioceramics and biocomposites as drug release matrices. J Controlled Release 2007;122:173-80.

34. Goyanes A, Buanz AB, Basit AW, Gaisford S. Fused-filament 3D printing (3DP) for fabrication of tablets. Int $\mathrm{J}$ Pharm 2014;476:88-92.

35. Lee BK, Yun YH, Choi JS, Choi YC, Kim JD. Fabrication of drugloaded polymer microparticles with arbitrary geometries using a piezoelectric inkjet printing system. Int J Pharm 2012;427:305-10.

36. Pardeike J, Strohmeier DM, Schrodl N, Voura C, Gruber M. Nano suspensions as advanced printing ink for accurate dosing of poorly soluble drugs in personalized medicines. Int J Pharm 2011;420:93-100.

37. Goyanes A, Det-Amornrat U, Wang J, Basit A, Gaisford S. 3D scanning and 3D printing as innovative technologies for fabricating personalized topical drug delivery systems. J Controlled Release 2016;234:41-8.

38. Brugger J. Inkjet printing | LMIS1 [Internet]. Lmis1.epfl.ch; 2018. Available from: https://lmis1.epfl.ch/page-34709.html. [Last accessed on 25 Mar 2018]

39. Popovic D. Automation and control in production processes, Control systems, robotics and automation. Industrial Appl Control System 2009;19:1-10.

40. Markarian J. Using robotics in pharmaceutical manufacturing, equipment and processing report, [Internet]. Pharmtech.com. 2014. Available from: http://www.pharmtech.com/usingrobotics-pharmaceutical-manufacturing. [Last accessed on 25 Mar 2018]

41. Invetech and Argos Therapeutics Announce Agreement [Internet]. Invetech. 2014. Available from: https://www.invetechgroup.com/news/2014/11/invetechand-argos-therapeutics-announce-agreement/. [Last accessed on 30 Mar 2018]

42. Twig L. Paperless manufacturing system, siemens product lifestyle management software, camstar enterprise [Internet] 2018. Available from: http://camstar.industrysoftware. automation.siemens. com/en/products-services/enterpriseplatform/camstar-manufacturing-execution-system/. [Last accessed on 26 Mar 2018]

43. Guidelines, Process performance and product quality monitoring system, Corrective action and preventive action (CAPA) system, FDA, ICH; 2009. p. 8-14.

44. Guidelines, Guidance for Industry Q10 Pharmaceutical Quality System, FDA, ICH; 2009. p. 1-19.

45. Gary Warren, Quality by Design (QbD); 2015. Available from: https://www.pda.org/docs/default-source/websitedocument-library/chapters/presentations/australia/qualityby-design-(qbd)-overview.pdf?sfvrsn $=6$ [Last accessed on 25 Mar 2018]

46. Godambe R, Disouza J, Jamkhandi C, Kumbhar P. Development of spectrophotometric and fluorometric methods for estimation of darunavir using QbD approach. Int J Curr Pharm Res 2018;10:13-9.

47. Nishendu P, Nadpara, Rakshit V, Thumar, Vidhi N, Kalola, et al. Quality by design (QbD): a complete review. Int J Pharm Sci Rev Res 2012;17:20-8.

48. Peraman R, Bhadraya K, Reddy Y. Analytical quality by design: a tool for regulatory flexibility and robust. Anal Int J Anal Chem 2015;1:1-9.

49. Ghante M, Shelar R, Sawant S, Kadam M. Development and validation UV-spectrophotometric method for estimation of darunavir ethanolate in bulk and tablet dosage form. Int J Pharma Pharm Sci 2014;6:240-2.

50. Balamuralikrishna K. Development and validation of analytical procedure for the simultaneous estimation of efavirenz, lamivudine and zidovudine through new RP-HPLC method. J Pharm Res 2011;4:3766-8.

51. Kamble R, Sharma S, Varghese V, Mahadik K. Process analytical technology (pat) in pharmaceutical development and its application. Int J Pharm Sci Rev Res 2013;23:212-23. 
52. Amit S, Anil P. Quality by design (QbD): a new concept for development of quality pharmaceuticals. Int J Pharm Quality Assurance 2017;4:13-9.

53. Mahalik N. Advances in packaging methods, processes and systems. Challenges 2014;5:374-89.

54. Bansal D, Malla S, Gudala K, Tiwari P. Anti-counterfeit technologies: a pharmaceutical industry perspective. Sci Pharm 2013;81:1-13.

55. Sanjay M, Sanjeev W. Multiple strategies and technologies to combat counterfeit drugs. [Internet] Computer sciences corporation USA; 2009. Available from: https://www. slideshare.net/guest696d96/multiple-strategies-andtechnologies-to combat-counterfeit-drugs. [Last accessed on 30 Mar 2018]

56. Guidelines, Therapeutic goods administration guideline for the Tamper-Evident packaging of medicines, complementary healthcare products and medical devices; 2000. Available from: https://www.tga.gov.au/publication/tamper-evidentpackaging-guideline. [Last accessed on 30 Mar 2018]

57. International medical products anti-counterfeiting taskforce anticounterfeit technologies for protection of medicines. WHO; 2009. Available from: http://www.who.int/medicines/ services/counterfeit/impact/IMPACT_AntiCountMeet.pdf. [Last accessed on 30 Mar 2018]

58. Print and Packaging-Elanders China [Internet]. Elanders.com; 2018. Available from: https://www.elanders.com/chi/printpackaging/. [Last accessed on 25 Mar 2018]

59. Iyer S. RFID technology and applications, IIT Bombay, [Internet] RFID; 2005. Available from: http://www.it.iitb. ac.in/ sri/talks/rfid-05.pdf. [Last accessed on 25 Mar 2018]

60. Alkhateeb F, Khanfar N, Loudon D. Physicians' adoption of pharmaceutical e-detailing: application of rogers' innovationdiffusion model. Services Marketing Quarterly 2009;31:116-32.

61. Parekh D, Kapupara P, Shah K. Digital pharmaceutical marketing: a review. Res J Pharm Technol 2016;1:108-12.

62. Nelson R. Electronic Batch Record Traceability-DataNinja [Internet]. DataNinja; 2018. Available from: https://www.dataninja.com/. [Last accessed on 25 Mar 2018]

63. Digital marketing strategies and technology innovation in the Pharmaceutical industry [Internet]. Slideshare.net; 2014. Available from: https://www.slideshare.net/ DigiTech
Strategies/ digital-marketing-strategies-and-technologyinnovation-in-the-pharmaceutical-industry. [Last accessed on 30 Mar 2018]

64. Rx Electronic Prescribing, Centers for medicare and medicaid services, [Internet]. cms.gov; 2016. Available from: https://www.cms.gov/Medicare/E-

Health/Eprescribing/index.html. [Last accessed on $25 \mathrm{Mar}$ 2018].

65. Electronic Repeat Dispensing (eRD): Dispenser guide, Northern, Eastern and Western Devon Clinical Commissioning Group. NHS Digital [Internet]. Newdevonccg.nhs.uk; 2016. Available

from:

https://www.newdevonccg.nhs.uk/information-forhealthcare-professionals/electronic-repeat-dispensing102194. [Last accessed on 25 Mar 2018]

66. Dermatology EMR software features-Bella Swan-Medium [Internet]. Medium; 2017. Available from: https://medium.com/@bellaa5046/dermatology-emrsoftware-features-65f6882c0dad. [Last accessed on 25 Mar 2018]

67. Callen J, Hordern A, Gibson K, Li L, Hains I, Westbrook J. Can technology change the work of nurses? Evaluation of a drug monitoring system for ambulatory chronic disease patients. Int J Med Inf 2013;82:71-6.

68. Goldman R, Soran C, Hayward G, Simon S. Doctors' perceptions of laboratory monitoring in office practice. J Eval Clin Pract 2010;16:1136-41.

69. Westbrook J, Ampt A. Design, application and testing of the work observation method by activity timing (WOMBAT) to measure clinicians' patterns of work and communication. Int J Med Inform 2009;78:25-33.

70. Prescription drug monitoring programs (pdmps) [Internet]. cdc.gov; 2018. Available from: www.cdc.gov/drugoverdose/ prescribing/guideline.html. [Last accessed on 25 Mar 2018]

71. Schiola E. Maintain your health and mind with these 15 medical apps [Internet]. Digital trends; 2016. Available from: https://www.digitaltrends.com/mobile/best-medical-apps/3/. [Last accessed on 25 Mar 2018]

72. iMagazin [Internet]; 2018. Available from: http://imagazin.hu/ az-5g-mobilhalozat-alapjaiban-fogja-megvaltoztatni-vilagot/. [Last accessed on 25 Mar 2018]. 